\title{
BRIDGING THE DIGITAL DIVIDE
}

\begin{abstract}
The Covid-19 crisis has added importance to contact-free transactions and maximum digitalization in every aspect of life. However, vast sections of societies in almost every country are not having access to modern information \& communication technology. This has resulted in a phenomenon known as the Digital Divide. Various socio-economic factors contribute to widening of this divide. If digitalization has to succeed faster, we need to bridge this gap as fast as possible. All stakeholders of ICT need to pool their resources and efforts to help in bridging the digital divide, by enhancing digital literacy and making it more affordable. This Paper is based on the speech delivered in the International online conference «New Digital Reality: Science and Education, Law, Security, Economics and Finance» held on July 6-10, 2020.
\end{abstract}

Key words: Digital Divide, Covid-19, Digital Literacy, Inequality, ICT, Digitalization.

DOI: 10.51180/RPS.2020.15.2.006.

\section{Author}

\section{Khatri Jagdish}

Prof., Ex-Director \& Chairholder UNESCO Network Chair, Mandsaur University,

(Mandsaur, India)

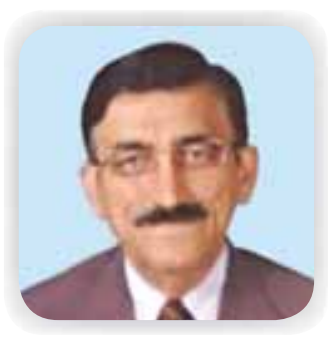

\section{Introduction}

$\mathrm{D}$ igitalization has been seen as a boon in the era of Covid-19 and lockdowns in keeping the momentum alive in all activities, especially in the Education, Finance and IT sectors. With people also seeking contact-free transactions, digitalization is being actively promoted.

Yet, the biggest obstacle in ensuring successful digitalization is the Digital Divide that exists in almost all regions, but often being ignored. The digital divide is the gap that exists between individuals who have access to modern information and communication technology and those who lack such access. As per a study by Deloitte in 2016, the US economy was losing \$130 million per day due to this digital divide.

\section{Different kinds of digital inequality}

Human societies are already riddled with various kinds of inequalities e.g. racial, educational, economic, social, etc. Now, there is another kind added to the list: Digital Inequality, which can be defined as "the gaps that are created in societies due to the lack of access and skills for digitalization".

Digital inequality is evident between:

- Urban and rural settlements

- Developed and underdeveloped economies

- Socio-economic groups

- Male and female genders

- Educated and uneducated people

Even where there is sufficient access to digital devices and networks, there are wide gaps among participants due to their inability to utilize it fully as they lack adequate skills to operate or knowledge about its all possibilities in shaping lives. This is known as Participation Inequality.

Digital Divide leads to:

- Widening of socio-economic inequalities

- Exclusion of a vast population from the benefits of digitalization 
Hence, there is an urgent need to address this phenomenon. If 'Bottom of the Pyramid' remains weaker, how can the upper layers sustain their prosperity, and for how long?

\section{Some suggestions for bridging the digital divide}

Some suggestions for bridging the digital divide are as follows:

- 3A's Strategy:

Make it: Accessible - Affordable Applicable

The first requirement is to make digitalization accessible to each and every individual at every remote corner, by creating and expanding the infrastructure and connectivity.

"The power of the Web is in its universality. Access by everyone regardless of disability is an essential aspect." -- Tim Berners-Lee, W3C Director and Inventor of the World Wide Web ${ }^{1}$

Secondly, make it affordable to all families. Reduce gradually the cost of equipment and internet connections; provide subsidies. Due to the Covid-19 crisis, educational institutions have resorted to online classes, assignments, and evaluation. There are unfortunate cases reported where young students committed suicide as they could not take these online assignments as their parents could not afford to buy smartphones or laptops for them.

Thirdly, develop relevant content that is immediately useful in providing solutions to different sections of learners. The

1 https://www.w3.org/WAl/EO/ Drafts/4betaW3org/ accessibility-neww3c200908131a\#: :text=Web\%20accessibility\%20 means\%20that\%20people,It\%20requires\%20 work. use of internet should not be limited only to infotainment, but also to help in making life easier.

- Digital Literacy Drive:

Make a strong campaign for expanding digital literacy for all sections of society. Digital literacy should not only mean computer operation ability or knowledge about hardware, software and internet. It should include a proper understanding of how digital devices can help in improving social, economic, cultural, environmental, physical, or personal aspects.

- Stakeholders Collaboration:

All the stakeholders of digitalization; e.g. Government, ICT Manufacturers, Scientists, Educational Institutions, Teachers, Trainers, Suppliers, Parents and Studentsthey all must come together to chalk out strategies and contribute in the spread of digitalization.

- Motivation \& Inclination:

There is also a need to develop intrinsic motivation to use digital technology. There is a portion of the global population that has the necessary income, education and computer literacy but has zero interest to learn about computers and the potential of the internet. Some view it as a luxury. Another group finds it too complicated to comprehend.

\section{Conclusion: benefits of digitalization}

Digitalization will help in the empowerment of individuals through extended learning opportunities and providing multi-skilling. This results in economic growth. Also, through ICT, we can have stronger social relationships and bonding. Provided that we can bridge these gaps, technology can be a great unifier for the whole of humanity.

\section{References}

1. Steele, C. (2019, February 22). What is the Digital Divide? The Digital Divide Council. — URL: http://www.digitaldividecouncil.com/what-is-the-digital-divide/

2. Steele, C. (2018, November 16). Top Five Digital Divide Solutions. The Digital Divide Council. - URL: http://www.digitaldividecouncil.com/top-five-digital-divide-solutions/

3. Steele, C. (2018, December 4). How to Bridge the Digital Divide. The Digital Divide Council. URL: http://www.digitaldividecouncil.com/how-to-bridge-the-digital-divide/ 